\title{
Conversion degree of indirect resin composites and effect of thermocycling on their physical properties
}

Souza, R O

\begin{abstract}
PURPOSE: This study evaluated the degree of conversion (DC) of four indirect resin composites (IRCs) with various compositions processed in different polymerization units and investigated the effect of thermal aging on the flexural strength and Vicker's microhardness. MATERIALS AND METHODS: Specimens were prepared from four IRC materials, namely Gr 1: Resilab (Wilcos); Gr2: Sinfony (3M ESPE); Gr3: VITA VMLC (VITA Zahnfabrik); Gr4: VITA Zeta (VITA Zahnfabrik) using special molds for flexural strength test $(\mathrm{N}=80, \mathrm{n}=10$ per group) ( $25 \times 2 \times 2 \mathrm{~mm}$ (3), ISO 4049), for Vicker's microhardness test $(\mathrm{N}=80, \mathrm{n}=10$ per group) $(5 \times 4 \mathrm{~mm}(2))$ and for DC $(\mathrm{N}=10)$ using FT-Raman Spectroscopy. For both flexural strength and microhardness tests, half of the specimens were randomly stored in distilled water at 37 degrees $C$ for 24 hours (Groups 1 to 4 ), and the other half (Groups 5 to 8 ) were subjected to thermocycling ( 5000 cycles, 5 to 55 +/- 1 degree C, dwell time: 30 seconds). Flexural strength was measured in a universal testing machine (crosshead speed: $0.8 \mathrm{~mm} / \mathrm{min}$ ). Microhardness test was performed at $50 \mathrm{~g}$. The data were analyzed using one-way and two-way ANOVA and Tukey's test (alpha= 0.05). The correlation between flexural strength and microhardness was evaluated with Pearson's correlation test (alpha = 0.05). RESULTS: A significant effect for the type of IRC and thermocycling was found $(p=0.001, p=0.001)$ on the flexural strength results, but thermocycling did not significantly affect the microhardness results $(p=0.078)$. The interaction factors were significant for both flexural strength and microhardness parameters $(\mathrm{p}=0.001$ and 0.002 , respectively). Thermocycling decreased the flexural strength of the three IRCs tested significantly $(p<$ 0.05), except for VITA Zeta $(106.3+/-9.1$ to $97.2+/-14 \mathrm{MPa})(\mathrm{p}>0.05)$ when compared with nonthermocycled groups. Microhardness results of only Sinfony were significantly affected by thermocycling $(25.1+/-2.1$ to 31 $+/-3.3 \mathrm{Kg} / \mathrm{mm}(2))$. DC values ranged between $63 \%$ and $81 \%$, and were not significantly different between the IRCs $(\mathrm{p}>0.05)$. While a positive correlation was found between flexural strength and microhardness without $(\mathrm{r}=0.309)$ and with thermocycling $(\mathrm{r}=0.100)$ for VITA VMLC, negative correlations were found for Resilab under the same conditions ( $\mathrm{r}=-0.190$ and -0.305 , respectively) (Pearson's correlation coefficient). CONCLUSION: Although all four IRCs presented nonsignificant DC values, flexural strength and microhardness values varied between materials with and without thermocycling. PMID: 20040031 [PubMed - indexed for MEDLINE]
\end{abstract}

DOI: https://doi.org/10.1111/j.1532-849X.2009.00551.x

Posted at the Zurich Open Repository and Archive, University of Zurich ZORA URL: https://doi.org/10.5167/uzh-44672

Journal Article

Originally published at:

Souza, R O (2010). Conversion degree of indirect resin composites and effect of thermocycling on their physical properties. Journal of Prosthodontics, 19(3):218-225.

DOI: https://doi.org/10.1111/j.1532-849X.2009.00551.x 


\title{
Conversion Degree of Indirect Resin Composites and Effect of Thermocycling on Their Physical Properties
}

\author{
Rodrigo O. A. Souza, DDS, MSc, ${ }^{1}$ Mutlu Özcan, Dr.Med.Dent., PhD, ${ }^{2}$ Silvia M. A. Michida, DDS, MSc, ${ }^{1}$ \\ Renata M. de Melo, DDS, MSc, ${ }^{1}$ Carlos A. Pavanelli, DDS, MSc, ${ }^{1}$ Marco A. Bottino, DDS, MSc, PhD, ${ }^{1}$ \\ Luís E. S. Soares, MSc, $\mathrm{PhD},{ }^{3}$ \& Airton A. Martin, MSc, $\mathrm{PhD}^{4}$

\footnotetext{
1 Department of Dental Materials and Prosthodontics, São Jose dos Campos Dental School, São Paulo State University, São Jose dos Campos, Brazil

${ }^{2}$ University of Zürich, Dental Materials Unit, Center for Dental and Oral Medicine, Clinic for Fixed and Removable Prosthodontics and Dental

Materials Science, Zürich, Switzerland

${ }^{3}$ Department of Dental Materials and Operative Dentistry, Faculty of Health Sciences, FCS, University of Vale do Paraíba, UNIVAP, São José dos Campos, Brazil

${ }^{4}$ Laboratory of Biomedical Vibrational Spectroscopy, Research and Development Institute, IPD, University of Vale do Paraíba, UNIVAP, São José dos Campos, Brazil
}

\section{Keywords}

Degree of conversion; flexural strength; indirect resin composites; Vicker's hardness.

\section{Correspondence}

Mutlu Özcan, University of Zürich, Dental Materials Unit, Center for Dental and Oral Medicine, Clinic for Fixed and Removable Prosthodontics and Dental Materials Science, Plattenstrasse 11, Zürich $\mathrm{CH}-8032$, Switzerland. E-mail:

mutluozcan@hotmail.com

Accepted March 3, 2009

doi: 10.1111/j.1532-849X.2009.00551.x

\begin{abstract}
Purpose: This study evaluated the degree of conversion (DC) of four indirect resin composites (IRCs) with various compositions processed in different polymerization units and investigated the effect of thermal aging on the flexural strength and Vicker's microhardness.

Materials and Methods: Specimens were prepared from four IRC materials, namely Gr 1: Resilab (Wilcos); Gr2: Sinfony (3M ESPE); Gr3: VITA VMLC (VITA Zahnfabrik); Gr4: VITA Zeta (VITA Zahnfabrik) using special molds for flexural strength test ( $\mathrm{N}=80, \mathrm{n}=10$ per group) $\left(25 \times 2 \times 2 \mathrm{~mm}^{3}\right.$, ISO 4049), for Vicker's microhardness test $\left(\mathrm{N}=80, \mathrm{n}=10\right.$ per group $\left(5 \times 4 \mathrm{~mm}^{2}\right)$ and for DC $(\mathrm{N}=10)$ using FT-Raman Spectroscopy. For both flexural strength and microhardness tests, half of the specimens were randomly stored in distilled water at $37^{\circ} \mathrm{C}$ for 24 hours (Groups 1 to 4), and the other half (Groups 5 to 8 ) were subjected to thermocycling (5000 cycles, 5 to $55 \pm$ $1{ }^{\circ} \mathrm{C}$, dwell time: 30 seconds). Flexural strength was measured in a universal testing machine (crosshead speed: $0.8 \mathrm{~mm} / \mathrm{min}$ ). Microhardness test was performed at $50 \mathrm{~g}$. The data were analyzed using one-way and two-way ANOVA and Tukey's test $(\alpha=$ $0.05)$. The correlation between flexural strength and microhardness was evaluated with Pearson's correlation test $(\alpha=0.05)$.

Results: A significant effect for the type of IRC and thermocycling was found ( $p=0.001, p=0.001)$ on the flexural strength results, but thermocycling did not significantly affect the microhardness results $(p=0.078)$. The interaction factors were significant for both flexural strength and microhardness parameters $(p=0.001$ and 0.002 , respectively). Thermocycling decreased the flexural strength of the three IRCs tested significantly $(p<0.05)$, except for VITA Zeta $(106.3 \pm 9.1$ to $97.2 \pm 14 \mathrm{MPa})$ $(p>0.05)$ when compared with nonthermocycled groups. Microhardness results of only Sinfony were significantly affected by thermocycling $(25.1 \pm 2.1$ to $31 \pm 3.3$ $\mathrm{Kg} / \mathrm{mm}^{2}$ ). DC values ranged between $63 \%$ and $81 \%$, and were not significantly different between the IRCs $(p>0.05)$. While a positive correlation was found between flexural strength and microhardness without $(r=0.309)$ and with thermocycling $(r=$ 0.100 ) for VITA VMLC, negative correlations were found for Resilab under the same conditions ( $r=-0.190$ and -0.305 , respectively) (Pearson's correlation coefficient). Conclusion: Although all four IRCs presented nonsignificant DC values, flexural strength and microhardness values varied between materials with and without thermocycling.
\end{abstract}


Photo-activated resin composites are commonly used restorative materials in dentistry for both anterior and posterior restorations. Such tooth-colored restorations can adhere to the dental tissues, and they can be made directly or indirectly at chairside or at the dental laboratory. One drawback of direct application of resin composites is the polymerization shrinkage that influences the stress produced at the interface between the dental tissues, leading to marginal gaps or hypersensitivity when the stress exceeds the bond strength between the resin composite and the tooth. ${ }^{1}$ Conversely, resin composite restorations built using indirect techniques result in lower polymerization shrinkage, reducing the stress between the tooth and the resin cement, avoiding postoperative sensitivity, with lower water sorption and, therefore, discoloration. ${ }^{1}$ Also with indirect resin composites (IRCs), less finishing and polishing time is required at chairside. IRCs do not require high technical skills, occlusal anatomy and proximal contacts can be established by the laboratory technician, and IRCs can be repaired when needed. ${ }^{2-6}$

IRC materials are usually classified according to the size of their inorganic particles; hybrid IRCs contain particles greater than $1.0 \mu \mathrm{m}$, microhybrid IRCs have particles smaller than 1.0 $\mu \mathrm{m}$, and nano-hybrid IRCs have particles smaller than $0.4 \mu \mathrm{m}$. The increase in the size and the volume of inorganic particles improves their resistance to wear, decreases the polymerization contraction, and also increases the glaze and polishability, which favors the esthetics. ${ }^{2,5}$

The degree of conversion (DC) has a significant influence on the physical ${ }^{5}$ and biological properties of resin composite restorations. DC is highly dependent on factors like composition of the material, ${ }^{7,8}$ color and translucency, ${ }^{9,10}$ distance of the light tip to the surface, and the irradiance of the polymerization lamp. ${ }^{11,12}$ In this context, IRCs allow for higher DC, as polymerization is carried out in the laboratory or at chairside in special photo-polymerization units in which all surfaces of the restoration can be polymerized. Depending on the type of the polymerization unit, combination of light, heat, vacuum, and pressure result in an improvement from $10 \%$ to $20 \%$ in the mechanical properties of these materials as opposed to the direct polymerization techniques. Unfortunately, with the increasing number and improved properties of IRCs, dental technicians and some clinicians have to invest not only in the IRC material itself, but also on polymerization lamps. Polymerization modes also show variations between several devices.

Many studies have been accomplished with the purpose of evaluating the mechanical properties of IRCs, ${ }^{10-17}$ especially with mechanical tests such as flexural strength and microhardness. ${ }^{10}$ The DC of monomers to polymers in dental resins has been evaluated using microhardness tests. ${ }^{9,15}$ While there is still no consensus in the dental literature as to which method should be used for the assessment of the DC, limited information is available on the mechanical properties of IRCs in aged conditions. ${ }^{18}$ In fact, like all other restorative materials, IRCs are also subjected to temperature variations in the oral cavity induced by diet. Temperature elevations and water uptake could cause degradation of the monomer matrix and filler/matrix interface $^{18}$ and consequently influence the strength of the IRCs. Hardness of the resin composites is also influenced by the type of light polymerization device. ${ }^{19}$
Flexural strength and fracture toughness tests are the most frequently used methods to evaluate the mechanical behavior of resin-based materials. ${ }^{17,18,20-22}$ Flexural strength tests can represent the dynamic nature of the existent stresses during mastication, creating different tensile, compression, and shear stresses upon fixed partial dentures (FPDs). ${ }^{17,18,22}$

This study evaluated the DC of four IRCs with various compositions polymerized in different devices, and also investigated the effect of thermal aging on the flexural strength and Vicker's microhardness of such composites. The null hypothesis tested was that there would be no difference between the mechanical properties and DC of IRCs before and after aging.

\section{Materials and methods}

The types, brand names, main compositions, corresponding polymerization modes, batch numbers, manufacturers, and the shades of the four IRCs used for the experiments are presented in Table 1 .

\section{Flexural strength test}

IRC specimens ( $\mathrm{N}=80, \mathrm{n}=10$ per group) were prepared in accordance with ISO $4049^{23}$ using a polyethylene mold $(25 \times 2$ $\times 2 \mathrm{~mm}^{3}$ ). They were polymerized according to each manufacturer's recommendation and wet-ground finished using silicone carbide papers up to 1200 grit. The specimens were then randomly divided into two groups. While half of the specimens were stored in distilled water at $37^{\circ} \mathrm{C}$ for 24 hours (Groups 1 to 4 ), the other half (Groups 5 to 8 ) were submitted to thermocycling (5000 cycles, 5 to $55 \pm 1{ }^{\circ} \mathrm{C}$, dwell time: 30 seconds, transfer time from one bath to the other: 2 seconds) (Nova Etica, São Paulo, Brazil).

The flexural strength tests were then performed in a universal testing machine (Model DL-1000, EMIC Equipments and Systems Ltd, Sao Jose dos, Brazil) where the load was applied at a constant transverse speed of $0.8 \mathrm{~mm} / \mathrm{min}$ until fracture. The formula in ISO $4049^{23}$ was followed for the calculation of the data obtained from the flexural strength test. The load that led to initial fracture of the specimens was obtained with the load cell having $50 \mathrm{kgf}$ capacity according to the following equation, where $P$ is the maximum load at fracture $(N), 1$ the distance between two parallel supports $(20 \mathrm{~mm}), \mathrm{b}$ width, and $\mathrm{d}$ thickness of the specimen $(\mathrm{mm})$ :

$$
\sum=\left(\frac{3 \mathrm{PL}}{2 \mathrm{bd}^{2}}\right)
$$

\section{Vicker's microhardness test}

Disc-shaped IRC specimens (diameter: $5 \mathrm{~mm}$; thickness: $4 \mathrm{~mm}$ ) $(\mathrm{N}=80)$ were prepared using a metal mold according to the polymerization process as described in Table 1 . The specimens were embedded in acrylic resin blocks, and each block was finished with wet silicone carbide papers up to 1200 grit and polished in a polishing machine (Struers, Model DP 10, Panambra Ind. \& Tec. S.A., São Paulo, Brazil) with diamond paste (3 $\mu \mathrm{m})$. While half the specimens were randomly stored in distilled water at $37^{\circ} \mathrm{C}$ for 24 hours (Groups 1 to 4 ), the other half 
Table 1 Indirect composite resins tested

\begin{tabular}{|c|c|c|c|c|c|c|c|}
\hline Type & $\begin{array}{l}\text { Brand } \\
\text { name }\end{array}$ & $\begin{array}{l}\text { Volume \% } \\
\text { inorganic } \\
\text { fillers }\end{array}$ & Main composition & Polymerization mode & $\begin{array}{l}\text { Batch } \\
\text { number }\end{array}$ & Manufacturer & Shade \\
\hline Microhybrid & Resilab & $53 \%$ & $\begin{array}{l}\text { Bis-GMA, UDMA, TEGMA, } \\
\text { Aluminium Borosilicate, } \\
\text { acid silicon of high } \\
\text { dispersal, photoinitiators, } \\
\text { inhibitors and pigments }\end{array}$ & $\begin{array}{l}\text { First cycle: Polymerization } \\
\text { for } 4 \mathrm{~min} \text { in the EDG-Lux } \\
\text { unit }\left(400-500 \mathrm{~mW} / \mathrm{cm}^{2}\right) \\
\text { Second cycle: } \\
\text { Polymerization for } 8 \text { min in } \\
\text { the EDG-Lux unit } \\
\left(400-500 \mathrm{~mW} / \mathrm{cm}^{2}\right)\end{array}$ & $156 / 05$ & $\begin{array}{l}\text { Wilcos do Brasil Ltd., } \\
\text { Petrópolis, Brazil }\end{array}$ & A2 \\
\hline Microhybrid & Sinfony & $50 \%$ & $\begin{array}{l}\text { HEMA and } 10 \% \text { to } 30 \% \\
\text { (octahydro-4,7-methano- } \\
1 \text { H-indenediyl) } \\
\text { bis(methylene)diacrylate), } \\
\text { strontium-aluminium } \\
\text { borosilicate glass, silicon } \\
\text { oxide, silane and } \\
\text { photoinitiators }\end{array}$ & $\begin{array}{l}\text { First cycle: Polymerization } \\
\text { for } 15 \mathrm{~s} \text { in the Visio Alpha } \\
\text { unit }\left(400 \mathrm{~mW} / \mathrm{cm}^{2}\right) \\
\text { Second cycle: } \\
\text { Polymerization for } 15 \mathrm{~min} \\
\text { in the Visio Beta unit ( } 470 \\
\left.\mathrm{~mW} / \mathrm{cm}^{2}\right)\end{array}$ & 203216 & 3M ESPE, St Paul, MN & A2 \\
\hline Microfilled & VITA VMLC & $46 \%$ & $\begin{array}{l}\text { UDMA, TEGMA, Silica, } \\
\text { primary particle (40-50 } \\
\text { nm) }\end{array}$ & $\begin{array}{l}\text { First cycle: Polymerization } \\
\text { for } 3 \text { min in the } \\
\text { Spectramat unit (350-500 } \\
\left.\mathrm{mW} / \mathrm{cm}^{2}\right) \\
\text { Second cycle: } \\
\text { Polymerization for } 5 \text { min in } \\
\text { the Spectramat unit } \\
\left(350-500 \mathrm{~mW} / \mathrm{cm}^{2}\right)\end{array}$ & 7677 & $\begin{array}{l}\text { Vita Zahnfabrik, Bad } \\
\text { Säckingen, Germany }\end{array}$ & A2 \\
\hline Microhybrid & VITA Zeta & $44 \%$ & $\begin{array}{l}\text { UDMA, TEGMA, Silica and } \\
\text { feldspar }\end{array}$ & $\begin{array}{l}\text { First cycle: Polymerization } \\
\text { for } 3 \text { min in the } \\
\text { Spectramat unit (350-500 } \\
\left.\mathrm{mW} / \mathrm{cm}^{2}\right) \text {. } \\
\text { Second cycle: } \\
\text { Polymerization for } 5 \text { min in } \\
\text { the Spectramat unit } \\
\left(350-500 \mathrm{~mW} / \mathrm{cm}^{2}\right)\end{array}$ & 7288 & $\begin{array}{l}\text { Vita Zahnfabrik, Bad } \\
\text { Säckingen, Germany }\end{array}$ & A2 \\
\hline
\end{tabular}

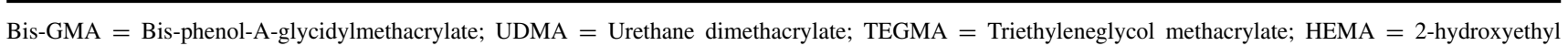
methacrylate.

(Groups 5 to 8 ) were submitted to thermocycling [5000 times, 5 to $55 \pm 1^{\circ} \mathrm{C}$, dwell time: 30 seconds, transfer time from one bath to the other: 2 seconds (Nova Etica)].

The microhardness measurements were made employing a Vicker's microhardness testing device (FM 700, Future-Tech, Equilam, Tokyo, Japan). The specimens were submitted to 50 $\mathrm{g}$ load for 30 seconds. Three readings were made at different regions on each specimen using the following equation, where $\mathrm{P}$ was the applied load in $\mathrm{Kg}$, and dv was the average of the diagonal length in $\mathrm{mm}:^{20}$

Vicker's microhardness $\left(\mathrm{Kg} / \mathrm{mm}^{2}\right)=1.8544 .\left(\frac{\mathrm{P}}{\mathrm{dv}^{2}}\right)$

\section{Degree of conversion}

Disc-shaped IRC specimens (diameter: $5 \mathrm{~mm}$; thickness: $4 \mathrm{~mm}$ ) $(\mathrm{N}=40)$ were prepared as described above. The specimens were stored in distilled water at $37^{\circ} \mathrm{C}$ for 24 hours and embed- ded in acrylic resin blocks. Each block was finished with wet silicone carbide papers up to 1200 grit and polished (Struers, Model DP 10) with diamond paste (3 $\mu \mathrm{m})$.

The surfaces were analyzed by FT-Raman Spectroscopy to evaluate the DC. The spectra of the uncured and cured resins were obtained by an FT-Raman Spectrometer (RFS 100/S, Bruker Inc, Karlsruhe, Germany) using 100 scans. The spectrum resolution was set to $4 \mathrm{~cm}^{-1}$. The specimens were excited by the defocused line of an Nd:YAG laser source at $\lambda=1064.1$ $\mathrm{nm}$ with maximum laser power of approximately $90 \mathrm{~mW}$ at the specimen. The uncured resin was positioned on an aluminium rod in a specimen holder mounted on an optical rail for spectrum collection. For the 80 cured specimens, three spectra of the top surface and another three spectra of the bottom surface were collected, resulting in a total of 480 spectra. Based on the measurements, one average spectrum for each surface was obtained, resulting in 160 spectra. The average FT-Raman spectra were analyzed by selecting a range between 1590 and $1660 \mathrm{~cm}^{-1}$. The Raman peaks corresponding to the vibrational stretching 
modes at 1610 and $1640 \mathrm{~cm}^{-1}$ were fitted in Gaussian shapes to obtain the height of the peaks by software (Microcal Software Inc, Northampton, MA). A comparison of the height ratio of the aliphatic carbon-carbon double bond $(\mathrm{C}=\mathrm{C})$ at $1640 \mathrm{~cm}^{-1}$ with that of the aromatic component at $1610 \mathrm{~cm}^{-1}$ for the cured and uncured conditions was performed to estimate the DC using the following equation:

$$
\begin{aligned}
\mathrm{R}_{\text {unpolymerized }} & =\frac{\text { band height at } 1640 \mathrm{~cm}^{-1}}{\text { band height at } 1610 \mathrm{~cm}^{-1}} \\
\mathrm{R}_{\text {polymerized }} & =\frac{\text { band height at } 1614 \mathrm{~cm}^{-1}}{\text { band height at } 1640 \mathrm{~cm}^{-1}}
\end{aligned}
$$

The aromatic $\mathrm{C}=\mathrm{C}$ peak at $1610 \mathrm{~cm}^{-1}$ originated from the aromatic bonds of the benzene rings in the monomer molecules, and its intensity remained unchanged during the polymerization reaction. The mean value and standard deviation of the DC were calculated for each series where $\mathrm{R}=$ the percentage of uncured resin determined by band height at $1640 \mathrm{~cm}^{-1} /$ band height at $1610 \mathrm{~cm}^{-1} .^{17}$

The percentage of DC was then calculated using the following equation:

$$
\mathrm{DC}(\%)=100 *\left[1-\left(\mathrm{R}_{\text {polymerized }} / \mathrm{R}_{\text {unpolymerized }}\right)\right]
$$

\section{Statistical analysis}

Statistical analysis was performed using Statistical Software for Windows (StatSoft Inc., version 5.5, 2000, Tulsa, OK) and Statistix for Windows (Analytical Software Inc., version 8.0, 2003, Tallahassee, FL). The means of each group from flexural strength and microhardness measurements were analyzed by two-way ANOVA, with the test type as the dependent variable and IRC types as the independent factors. $P$ values less than 0.05 were considered to be statistically significant in all tests. Multiple comparisons were made by Tukey's adjustment test. DC values were analyzed using one-way ANOVA. The correlation between flexural strength and microhardness measurements was evaluated using Pearson's correlation test $(p<$ $0.05)$.

\section{Results}

The type of IRC and thermocycling had a significant effect ( $p=$ $0.001, p=0.001$, respectively) on the flexural strength results, but thermocycling did not significantly affect the microhardness results $(p=0.078)$. The interaction factors for both flexural strength and microhardness parameters were significant ( $p=$ $0.001, p=0.002$ ) (Tables 2 and 3).

\section{Flexural strength test}

After thermocycling, the flexural strength of the three IRCs tested decreased [(Sinfony: $177.1 \pm 45.4$ to $127.2 \pm 15.1$, Resilab: $200 \pm 42$ to $112 \pm 17.1$, VITA VMLC: $147.4 \pm 28$ to $77 \pm 19 \mathrm{MPa})]$ significantly $(p<0.05)$ except for VITA Zeta $(106.3 \pm 9.1$ to $97.2 \pm 14 \mathrm{MPa})(p>0.05)($ Table 4, Fig 1$)$.
Table 2 Two-way ANOVA for the indirect resin composite types and the interaction terms after flexural strength test, $\left(^{*} p<0.05\right)$

\begin{tabular}{lrrrrc}
\hline Effect & DF & \multicolumn{1}{c}{ SS } & MS & $F$ & $p$ \\
\hline Resins & 3 & 45,211 & 15,070 & 21.02 & $0.001^{*}$ \\
Thermocycling & 1 & 59,205 & 59,205 & 82.58 & $0.001^{*}$ \\
Interaction & 3 & 17,282 & 5761 & 8.04 & $0.001^{*}$ \\
Residue total & 72 & 51,618 & 717 & & \\
Total & 79 & 173,315 & & & \\
\hline
\end{tabular}

\section{Vicker's microhardness test}

The microhardness results of Sinfony were significantly affected by thermocycling $\left(25.1 \pm 2.1\right.$ to $\left.31 \pm 3.3 \mathrm{Kg} / \mathrm{mm}^{2}\right)$ (Table 5, Fig 2).

\section{Degree of conversion}

DC of all four IRCs did not show significant differences between the experimental groups $(75 \pm 2 ; 75 \pm 11 ; 63 \pm 10$; $81 \pm 12 \%$ for Resilab, Sinfony, Vita VMLC, and Vita Zeta, respectively) ( $p>0.05$ ) (one-way ANOVA). Micro-Raman spectra of the IRCs are presented in Figure 3.

The correlation between flexural strength and microhardness was evaluated. The Pearson's correlation coefficient (r) can range from -1 to 1 , inclusive. Positive values indicate a positive correlation, negative values indicate negative correlation, and when $r$ is 0 , there is no correlation between the factors. Additionally, $r$ values closer to +1 or -1 indicate strong positive or negative correlation, respectively, whereas $r$ values further away from +1 or -1 indicate weak positive and negative correlation, respectively. While a positive correlation was found between flexural strength and microhardness values without ( $\mathrm{r}=0.309$, weak correlation) and with thermocycling $(\mathrm{r}=$ 0.100 , weak correlation) for VITA VMLC, weak negative correlations were found for Resilab in the same conditions ( $\mathrm{r}=$ -0.190 and -0.305 , respectively) (Pearson's correlation coefficient)(Fig 4).

\section{Discussion}

Evolution in the field of polymer technology has made the fabrication of metal-free restorations possible using IRCs, particularly due to the improvement in their physical properties. ${ }^{24}$ Flexural strength values obtained from the IRCs tested in this study (106 to $200 \mathrm{MPa}$ ) without thermocycling were similar to

Table 3 Two-way ANOVA for the indirect resin composite types and the interaction terms after Vicker's microhardness test, $\left({ }^{*} p<0.05\right)$

\begin{tabular}{lrrrrr}
\hline Effect & DF & \multicolumn{1}{c}{ SS } & MS & $F$ & $p$ \\
\hline Resins & 3 & 8434.5 & 2811.5 & 202.38 & $0.001^{*}$ \\
Thermocycling & 1 & 44.4 & 44.4 & 3.20 & 0.078 \\
Interaction & 3 & 235.0 & 78.3 & 5.64 & $0.002^{*}$ \\
Residue total & 72 & 1000.2 & 13.9 & & \\
Total & 79 & 9714.2 & & & \\
\hline
\end{tabular}


Table 4 The mean ( \pm standard deviation) flexural strength values (MPa) for indirect resin composites before and after thermocycling. *The same superscript letters indicate no significant differences (Tukey's test, $p<$ $0.05)$

\begin{tabular}{lcc}
\hline \multirow{2}{*}{ Experimental groups } & \multicolumn{2}{c}{ Thermocycling } \\
\cline { 2 - 3 } & Without & With \\
\hline Resilab (Groups 1 and 5) & $200 \pm 42^{\mathrm{a}}$ & $112 \pm 17.1^{\mathrm{c}, \mathrm{d}, \mathrm{e}}$ \\
Sinfony (Groups 2 and 6) & $177.1 \pm 45.4^{\mathrm{a}, \mathrm{b}}$ & $127.2 \pm 15.1^{\mathrm{c}, \mathrm{d}}$ \\
VITA VMLC (Groups 3 and 7) & $147.4 \pm 28^{\mathrm{b}, \mathrm{c}}$ & $77 \pm 19^{\mathrm{f}}$ \\
VITA Zeta (Groups 4 and 8) & $106.3 \pm 9.1^{\mathrm{d}, \mathrm{e}}$ & $97.2 \pm 14^{\mathrm{d}, \mathrm{e}}$ \\
Mean & $158 \pm 48.3$ & $103.2 \pm 24.4$ \\
\hline
\end{tabular}

those observed in other studies on IRCs (120 to $160 \mathrm{MPa}$ for ArtGlass, Heraeus-Kulzer and Targis, Ivoclar Vivadent). ${ }^{18,25-27}$ Such resin composites are examples of second-generation IRCs, and the flexural strength values make their indication possible for inlays, onlays, FPDs, and FPDs reinforced with fibers. ${ }^{28}$ According to the International Organization for Standardization (ISO 4049), ${ }^{23}$ IRCs should present a minimum flexural strength of $100 \mathrm{MPa}$ in order to be indicated for such restorations. The results of our study exceeded the value required by ISO 4049 , regardless of the IRCs and polymerization units used; however, three of the tested IRCs, (Resilab, Sinfony, VITA VMLC) showed a significant decrease in flexural strength values after 5000 thermocycles. Therefore, the hypothesis that hydrothermal aging would decrease the flexural strength of the IRC could only be partially accepted. High or elevated temperatures are known to weaken the resin-based materials. ${ }^{16,29}$

Thermocycling is a combination of hydrolytic and thermal degradation and a method to simulate temperature-related breakdown by repeated sudden temperature changes. Particularly in the case of Sinfony, a decrease in the flexural strength after thermocycling was noticed in almost $50 \%$ of specimens. Although the curing time for Sinfony was longer (15 minutes) than those of the other IRCs ( 8 to $12 \mathrm{~min}$ utes), lower results were achieved, which could be due to the differences in monomer types of the IRCs. While Sinfony contains HEMA at $10 \%$ to $30 \%$ (octahydro-4,7-methano- $1 \mathrm{H}-$ indenediyl)bis(methylene)diacrylate, the other three IRCs con-

\section{Flexural Strength (MPa)}

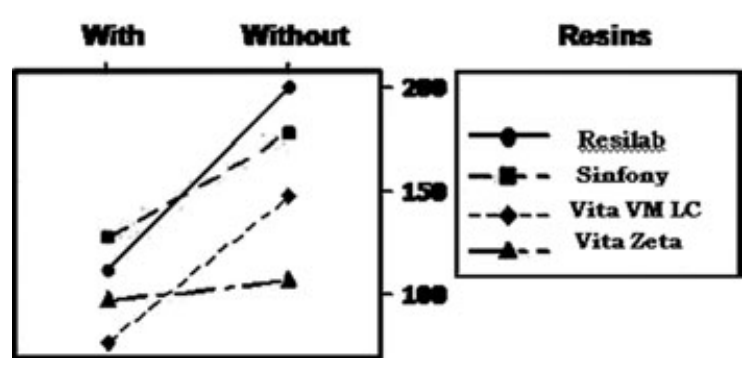

Figure 1 Flexural strength test results with and without thermocycling for the indirect resin composites tested.
Table 5 The mean ( \pm standard deviation) Vicker's microhardness values $\left(\mathrm{Kg} / \mathrm{mm}^{2}\right)$ for indirect resin composites before and after thermocycling. *The same superscript letters indicate no significant differences (Tukey's test, $p<0.05)$

\begin{tabular}{lcr}
\hline & \multicolumn{2}{c}{ Thermocycling } \\
\cline { 2 - 3 } Experimental groups & Without & With \\
\hline Resilab (Groups 1 and 5) & $53 \pm 6^{\mathrm{a}}$ & $55 \pm 6.4^{\mathrm{a}}$ \\
Sinfony (Groups 2 and 6) & $25.1 \pm 2.1^{\mathrm{c}}$ & $31 \pm 3.3^{\mathrm{b}}$ \\
VITA VMLC (Groups 3 and 7) & $34.4 \pm 2.3^{\mathrm{b}}$ & $30.5 \pm 3.1^{\mathrm{b}}$ \\
VITA Zeta (Groups 4 and 8) & $30 \pm 2^{\mathrm{b}, \mathrm{c}}$ & $32 \pm 2^{\mathrm{b}}$ \\
Mean & $35.4 \pm 11.1$ & $36.92 \pm 11.2$ \\
\hline
\end{tabular}

tain some UDMA in their composition. The results obtained with IRCs having UDMA are comparable to those reported in Yamaga et al's study. ${ }^{10}$ In that study, even higher hardness and fracture toughness values were found with IRCs containing four-functional urethane methacrylate (UTMA) than those of two-functional UDMA. In fact, it has already been shown that increased contents of UDMA increase the flexural strength of experimental resins. ${ }^{30}$ In Kakaboura et al's study, ${ }^{24}$ BelleGlass HP exhibited significantly higher DC and mechanical properties compared to Sinfony. Also, Gohring et $\mathrm{al}^{31}$ studied several IRCs and found the lowest flexural strength with Sinfony. Based on these previous observations and ours, it seems that Sinfony composition plays a major role in its flexural strength. In this case, increasing the light-exposure time could be a solution to obtaining a higher DC. ${ }^{32}$ Furthermore, because it is flowable, Sinfony is more likely to contain voids that might influence the flexural strength results. ${ }^{33}$ In this context, besides requiring the IRC compositions and their corresponding polymerization device, ISO requirements should also take aging factors into consideration. It can be anticipated that, depending on the number of thermal cycles, more degradation on the resins is likely to occur.

Surface hardness measurement is a simple technique that facilitates the evaluation of a large number of specimens. Although it was found to be a good predictor for resin conversion, it was also reported to be especially sensitive to small changes of the polymer cross-linking in areas of high conversion. ${ }^{15}$ Even though hardness values may not be used for a direct comparison among materials, they are valuable tools for relative measurements within the same material, and their simplicity makes

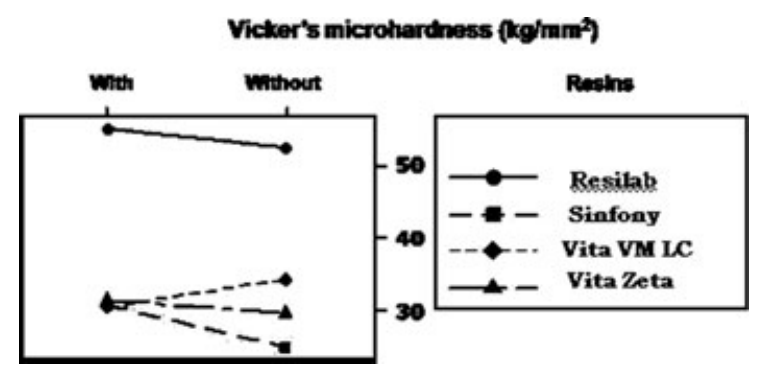

Figure 2 Vicker's microhardness results with and without thermocycling for the indirect resin composites tested. 


\section{Micro Raman Spectra}

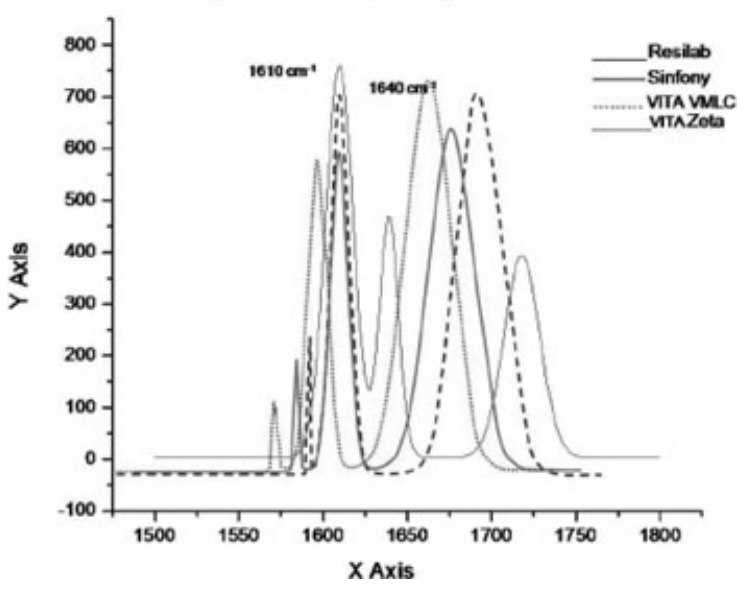

Figure 3 Micro-Raman spectra of the indirect resin composites tested.

them suitable for comparison between different polymerization techniques. ${ }^{34}$

Vicker's microhardness is dependent on the extension of the polymeric matrix polymerization and the quantity of inorganic fillers of the resin. ${ }^{35}$ Although the DCs were not significantly different, there were significant differences between the microhardness values, again leading to partial acceptance of the first hypothesis. Despite the fact that the polymerization devices employed had similar light output, only VITA Zeta and VITA VMLC (similar monomer matrices, polymerized under the same conditions) did not show significant differences in microhardness. A previous study showed that the filler content in the IRC tended to be linearly proportional to both hardness and fracture toughness. ${ }^{10}$ The filler content in volume percentage was similar in all materials tested. In this study, the differences in microhardness cannot be attributed to differences in DC, as it was not significantly different between the groups. This strengthens the fact that mechanical properties do not always work as a function of DC, which requires further investigation.

The differences in microhardness obtained with three IRCs polymerized with three different light sources are best explained by the polymerization mode of the equipment used or the monomer matrix type. After thermocycling, the mean microhardness values of other IRCs were not significantly changed, but interestingly, only Sinfony showed significantly higher results. It may be that dwelling at $55^{\circ} \mathrm{C}$ water bath during thermocycling contributed to further polymerization of the surface, initially leading to increased hardness. Prolonged thermocycling may lead to water absorption by a diffusion-controlled process, and it causes leaching of unreacted monomers and
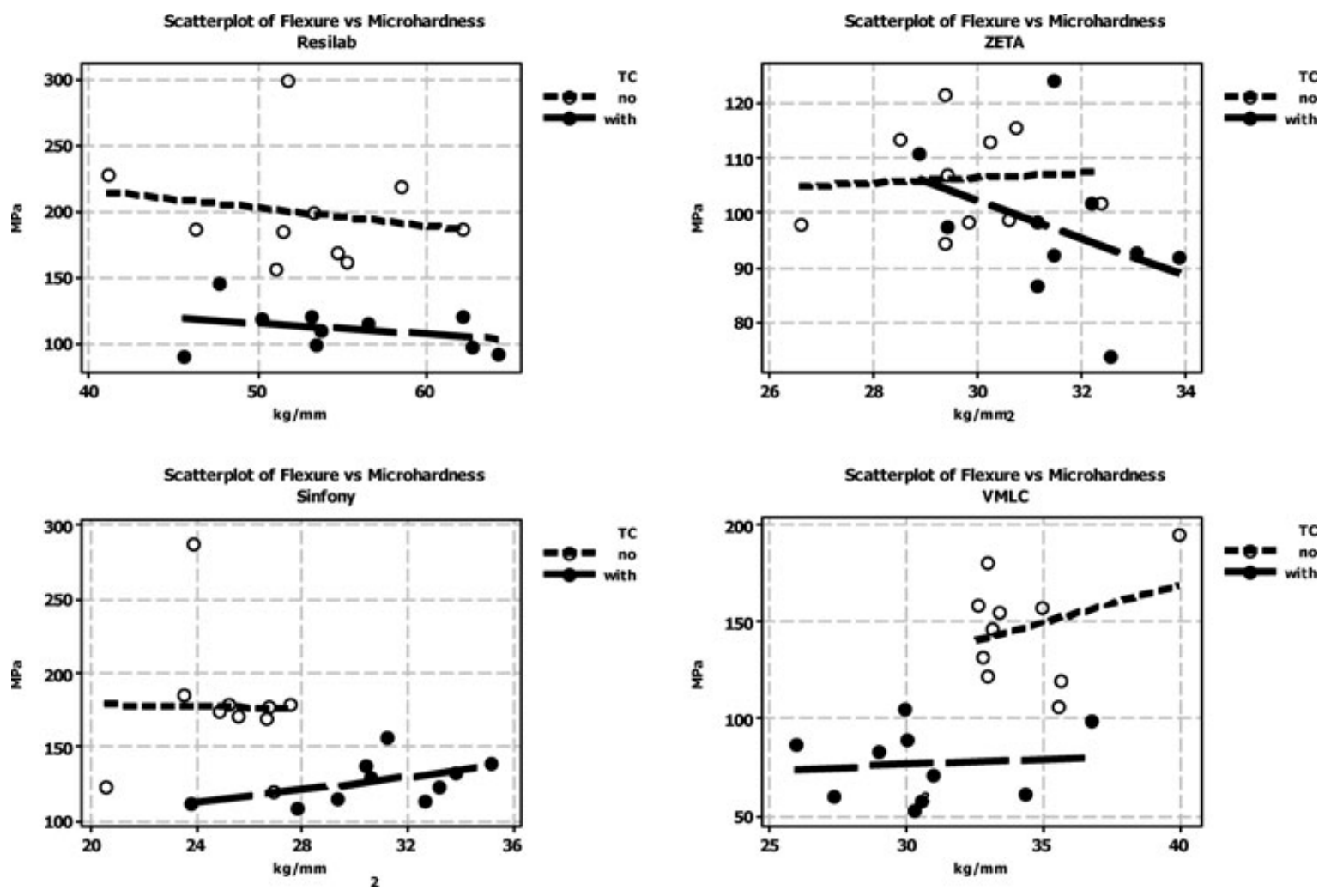

Figure 4 Scatter plot of correlation values between flexural strength (MPa) and Vicker's microhardness $\left(\mathrm{Kg} / \mathrm{mm}^{2}\right)$ for Resilab $(r=-0.190, p=0.600$; $r=-0.305, p=0.391)$; VITA Zeta $(r=0.077, p=0.832 ; r=-0.394, p=0.260) ;$ Sinfony $(r=-0.016, p=0.965 ; r=0.477, p=0.163) ;$ VITA VMLC $(r=0.309, p=0.385 ; r=0.100 ; p=0.783)$ without and with thermocycling (TC), respectively. 
swelling of the matrix. Water acts like a plasticizer and thereby weakens the polymer structure. It also degrades the matrix/filler interface directly by hydrolytic breakdown of the silane/filler interface and the surface of the filler particles. ${ }^{36}$ Unfortunately, the minimal number of thermocycles necessary for plasticization is not known.

While a positive but weak correlation was found between flexural strength and microhardness for VITA VMLC with and without thermocycling, negative correlations were found for Resilab under the same conditions. The findings of this study need to be confirmed on a larger number of specimens. Measurements of behavior (hardness, Young modulus) are more sensitive than spectroscopy for following slow changes in the DC when the network is fully cross-linked in aging experiments. Leung et $\mathrm{al}^{33}$ concluded that the best technique to evaluate the DC was Fourier transformation infrared spectroscopy(FTIR), even though the hardness measurement provided good information. On the other hand, the study conducted by Rueggeberg and $\mathrm{Craig}^{35}$ revealed that the hardness measurement is more sensitive than FTIR for detecting the small changes in the DC and following the change occurring in the first stages of polymerization after the network is cross-linked.

In FTIR evaluations, it was found that UEDMA/TEGDMA phase had a DC of $70 \%$ and exhibited superior wear resistance, while Bis-GMA/TEGDMA had a DC of 55\% when conventional resin composites were used. ${ }^{37}$ Monomer mixtures of Bis-GMA and TEGDMA give rise to polymers in which the quantity of remaining double bonds increases with the content of Bis-GMA, without the mechanical properties being significantly affected. ${ }^{38}$ The DC results obtained in this study with the tested IRCs were slightly higher than those reported previously with the conventional resin composites for direct applications. There were variations between the DC values of the IRCs, but the results were not statistically significant. Currently available IRCs are mostly polymerized by xenoscopic light devices in which a higher DC is expected as a result of heat and light combination. ${ }^{25}$ Therefore, polymerization processes and their effect on the mechanical and chemical properties of IRCs show variations, and this should be taken into consideration when choosing IRCs for clinical applications. ${ }^{39}$

\section{Conclusions}

From this study, the following could be concluded:

1. The degree of polymer crosslink assessed by FT-Raman Spectroscopy did not correspond to the resulting mechanical behavior of the materials tested.

2. Although the microhardness of Sinfony was affected by thermocycling, 5000 thermocycles did not decrease the microhardness of the majority of the IRCs. On the contrary, thermocycling decreased the flexural strength of most IRCs studied, except for VITA Zeta.

3. IRCs designed for the same applications may present different mechanical behavior.

\section{References}

1. Hickel R, Manhart J: Longevity of restorations in posterior teeth and reasons for failure. J Adhes Dent 2001;3:45-64

2. Kildal KK, Ruyter IE: How different curing methods affect mechanical properties of composites for inlays when tested in dry and wet conditions. Eur J Oral Sci 1997;105:353-361

3. Özcan M, Alander P, Vallittu PK, et al: Effect of three surface conditioning methods to improve bond strength of particulate filler resin composites. J Mater Sci: Mater Med 2005;16:21-27

4. The Dental Advisor: Laboratory composites; 1999

5. The Dental Advisor: Microhybrid and microfilled composites; 2000

6. Touati B, Aidan N: Second generation laboratory composite resins for indirect restorations. J Esthet Dent 1997;9:108-118

7. Nash RW: Processed composite resin-a versatile restorative material. Compend Contin Educ Dent 2002;23:142-158

8. The Dental Advisor: 18-Year report on laboratory composites; 2003

9. Wendt SL: The effect of heat used as the secondary cure upon the physical properties of three composite resins. I. Diametral tensile strength, compressive strength and marginal dimensional stability. Quintessence Int 1987;18:265-271

10. Yamaga T, Sato Y, Akagawa Y, et al: Hardness and fracture toughness of four commercial visible light-cured composite resin veneering materials. J Oral Rehabil 1995;22:857-863

11. Peutzfeldt A, Asmussen E: Mechanical properties of three composite resins for the inlay/onlay technique. J Prosthet Dent 1991;66:322-324

12. Peutzfeldt A, Asmussen E: The effect of postcuring on quantity of remaining double bonds, mechanical properties, and in vitro wear of two resin composites. J Dent 2000;28:447-452

13. Erdrich AJ: ArtGlass: a unique polyglass technology for prosthetic and restorative dentistry. The Laboratory Digest 1996;2-3

14. Freiberg RS, Ferracane JL: Evaluation of cure, properties and wear resistance of ArtGlass dental composite. Am J Dent 1998;11:214-218

15. Mandikos MN, McGivney GP, Davis E, et al: A comparison of the wear resistance and hardness of indirect composite resins. J Prosthet Dent 2001;85:386-395

16. Rossomando KJ, Wendt SL Jr: Thermocycling and dwell times in microleakage evaluation for bonded restorations. Dent Mater 1995; $11: 47-51$

17. Palin WN, Fleming GJP, Burke FJT, et al: The reliability in flexural strength testing of a novel dental composite. J Dent 2003;31:549-557

18. Kawano F, Ohguri T, Ichikawa T, et al: Influence of thermal cycles in water on flexural strength of laboratory-processed composite resin. J Oral Rehabil 2001;28:703-707

19. Friedman J, Hassan R: Comparison study of visible curing lights and hardness of light-cured restorative materials. J Prosthet Dent 1984;52:504-506

20. Zhao D, Botsis J, Drummond JL: Fracture studies of selected dental restorative composites. Dent Mater 1997;13:198-297

21. Anusavice KJ: Phillip's Science of Dental Materials (ed 10). Philadelphia, Saunders, 1996; p. 46

22. Lu H, Mehmood A, Chow A, et al: Influence of polymerization mode on flexural properties of esthetic resin luting agents. J Prosthet Dent 2005;94:549-554

23. International Organization for Standardization: Specification of dentistry-resin-based filling materials. ISO-4049;1988

24. Kakaboura A, Rahiotis C, Zinelis S, et al: In vitro characterization of two laboratory-processed resin composites. Dent Mater 2003;19:393-398 
25. Knobloch LA, Kerby RE, Seghi R, et al: Two-body wear resistance and degree of conversion of laboratory-processed composite materials. Int J Prosthodont 1999;12:432-438

26. Neves AD, Discacciati JA, Orefice RL, et al: Influence of the power density on the kinetics of photopolymerization and properties of dental composites. J Biomed Mater Res Part B: Appl Biomat 2005;72:393-400

27. St-Georges A, Swift Jr. E, Thompson JY, et al: Irradiance effects on the mechanical properties of universal hybrid and flowable hybrid resin composites. Dent Mater 2003;19:406-413

28. Gauthier MA, Stangel I, Ellis TH, et al: Oxygen inhibition in dental resins. J Dent Res 2005;84:725-729

29. Ferracane JL, Berge HX, Condon JR: In vitro aging of dental composites in water-effect of degree of conversion, filler volume, and filler/matrix coupling. J Biomed Mater Res Part B: Appl Biomat 1998;42:465-472

30. Asmussen E, Peutzfeldt A: Influence of UEDMA, BisGMA and TEGDMA on selected mechanical properties of experimental resin composites. Dent Mater 1998;14:51-56

31. Gohring TN, Gallo L, Luthy H: Effect of water storage, thermocycling, the incorporation and site of placement of glass-fibers on the flexural strength of veneering composite. Dent Mater 2005;21:761-772
32. Spencer P, Wang Y, Bohaty B: Interfacial chemistry of moisture-aged class II composite restorations. J Biomed Mater Res Part B: Appl Biomat 2006; 77:234-240

33. Leung RL, Kahn RL, Fan PL: Comparison of depth of polymerization evaluation methods for photo-activated composite. J Dent Res 1984;63:292-296

34. Drummond JL: Degradation, fatigue, and failure of resin dental composite materials. J Dent Res 2008;87:710-719

35. Rueggeberg FA, Craig RG: Correlation of parameters used to estimate monomer conversion in a light-cured composite. J Dent Res 1988;67:932-937

36. Beun S, Glorieux T, Devaux J, et al: Characterization of nanofilled compared to universal and microfilled composites. Dent Mater 2007;23:51-59

37. Ferracane JL, Greener EH: The effect of resin formulation on the degree of conversion and mechanical properties of dental restorative resins. J Biomed Mater Res 1986;20:121-131

38. Asmussen E, Peutzfeldt A: Influence of pulse-delay curing on softening of polymer structures. J Dent Res 2001;80:15701573

39. Souza ROA, Özcan M, Michida MA, et al: Conversion degree and thermocycling effect on physical properties of indirect resins. J Dent Res (Abstract\# 0092), 2006;Special Issue A:236 